\title{
Dosimetry Measurements of X-Ray and Neutron Radiation Levels Near the Shuttle and End Beam Dump at the Advanced Test Accelerator
}

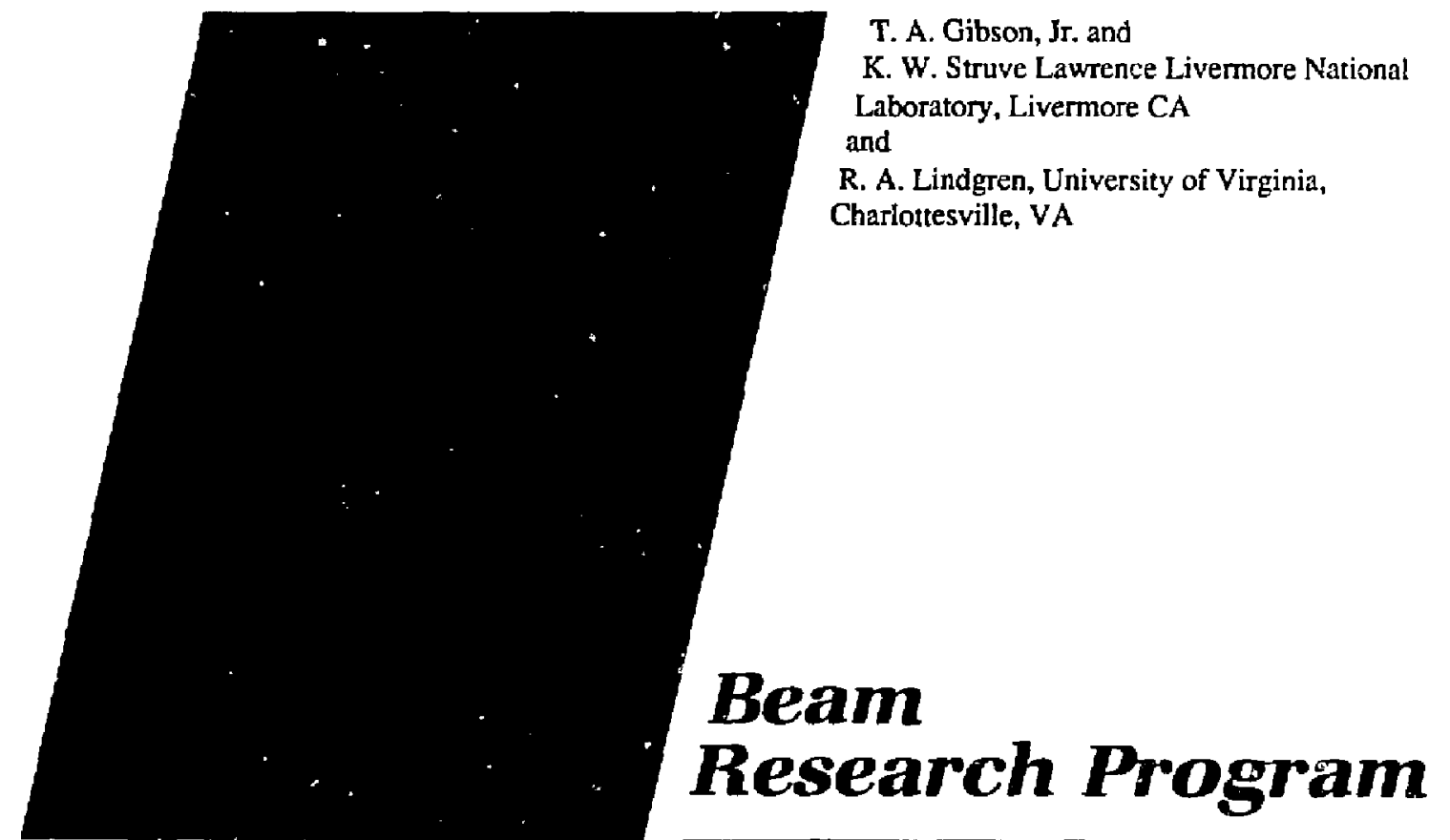

Lawrence Livermore National Laboratory

Work performed jointly unde $P$ the euppites or the U.S. Defertment

of E nerry by Lan rence Liver more Nationel Laberttory under Contruet

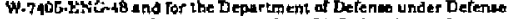

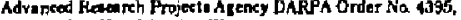

monitared by Nural Surface Weanons Center under document number

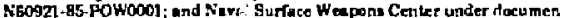
number N60521-65-WTHOO201. 
This dexument was prepared as an axcount of work ponered by an agency of the Uniled Stales Governoment Neither the United Sta:es Covernment nor the University of Caljfornia nor any of their employeel, takces any

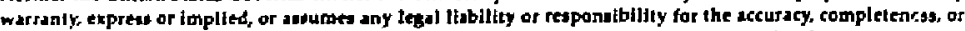
usefulnews of any information. apparatus, product, dt procest diselosed, or represent ihat is, we would nol infringe privately owned nghla. Relerence herein to any specific eommetcial products, pacess, or service by tride name, trademark, manufacturer, or otherwise, does not necesuarily constilute or imply tis endorsement, tecommendation, of taroring by the United Stales Govemmenl ar the University af California. The viewa and opinians of authats expressed herein do not neceusily atste of selecl those of the Uaited States Government ns the Liniverbily of California, and ghall not be used for advertising of product endarsemeat purposes.

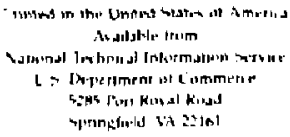

Price

Code

A01

Papercopy Prices l'age

Range

$\begin{array}{ll}\text { A.2 } & \text { A01-050 } \\ \text { A03 } & 051-100 \\ \text { A04 } & 101-200 \\ \text { A05 } & 201-300 \\ \text { A06 } & 301-\$ 00 \\ \text { A07 } & 401-500 \\ \text { A08 } & 501-600 \\ \text { A09 } & \text { CO1 }\end{array}$

\section{DISCLAJMER}

This repart was pret

Govetnment as prepired as an acco

emplayees, makes any wasranty, expres Governmenr nor any an agency of the Uniled Siates bility for the aceuracy. compleleness, or or implind, or assumes any tegereuf, nor any of their proce is disclused, or represents that its use wouldess of any information, appaibility or responsi. manufacturet, any spocific commercial use would nol infriage privdtely awates. product, of manufactures, or otherwise does not pecessact. process, or service by teatend rights. Referand opinions favoring by the United Staterify conslitule or imply ists endame, trademark. Unded State of authors expressed hertion Govesnment of any agency istsement, recomUnited States Government or any agetein do not necessarily any agency thereur. The views Gernment or ary agency thescof.
. 


\section{DOSIMETRY MEASUREMENTS OF X-RAY AND NEUTRON \\ RADIATION LEVELS NEAR THE SHUTTLE AND END BEAM DUMP AT THE \\ ADVANCED TEST ACCELERATOR}

\section{INTRODUCTION}

Electron beams as a source of directed energy are under study at the Lawrence Livermore National Laboratory (LLNL). An intense 10-kA, 50-MeV, 50-ns full-width half-maximum, pulsed electron beam is generated by the prototype Advanced Test Accelerator (ATA) at the Laboratory's Site 300 . The ATA is being used to conduct precursor experiments that ultimately will lead to the crucial test of electron beam propagation in the atmosphere. Whenever the electron beam is stopped in materials, intense radiation is generated. Estimates based on available data in the literature show that for materlals such as lead, photon radiation ( $x$ ray, gamma, bremstrahlung) levels can be as large as $10^{4}$ roentgens per pulse at $1 \mathrm{~m}$ in the zero-degree direction 6 i.e.. the electron-beam direction). Neutrons, which are emitted isotropically, are produced at a level of $10^{13} \mathrm{n} / \mathrm{m}^{2}$ per pulse. ${ }^{2}$ Depending upon the number of pulses and the shielding geometry, the accumulated dose is potentially lethal to personnel and potentially damaging to instrumentation that may be used for diagnostics.

To provide shielding for minimizing the risk of exposure to personnel and radiation damage to instrumentation, it is important to determine the $x$-ray and neutron radiation environment near beamine components such as the beam shuttle dump and beam stop. Photon and neutron dosimetry measurements were performed around the beam shuttle dump on January 9 , 1985, and near the carbon beam stop at the end of the beamline before the entrance to the diagnostic tunnel on April 12 and December 23, 1985. These measurements together with 5 imple rule-of-thumb estimates and Monte Carlo electron-photon shower calculations of the absorbed dose are presented in this report.

\section{Experimental Procedure}

An intense source of $x-r a y$ and neutron radiation in the ATA beam-handling system is the beam shuttle dump, which is used to stop the beam during beam-diagnostics studies. A schematic cross-sectional view looking upstream in the shuttle dump is shown in Figure 1 . The electron beam is actually stopped in a series of water-cooled carbor plates haying smatl apertures.

\section{MASTER}




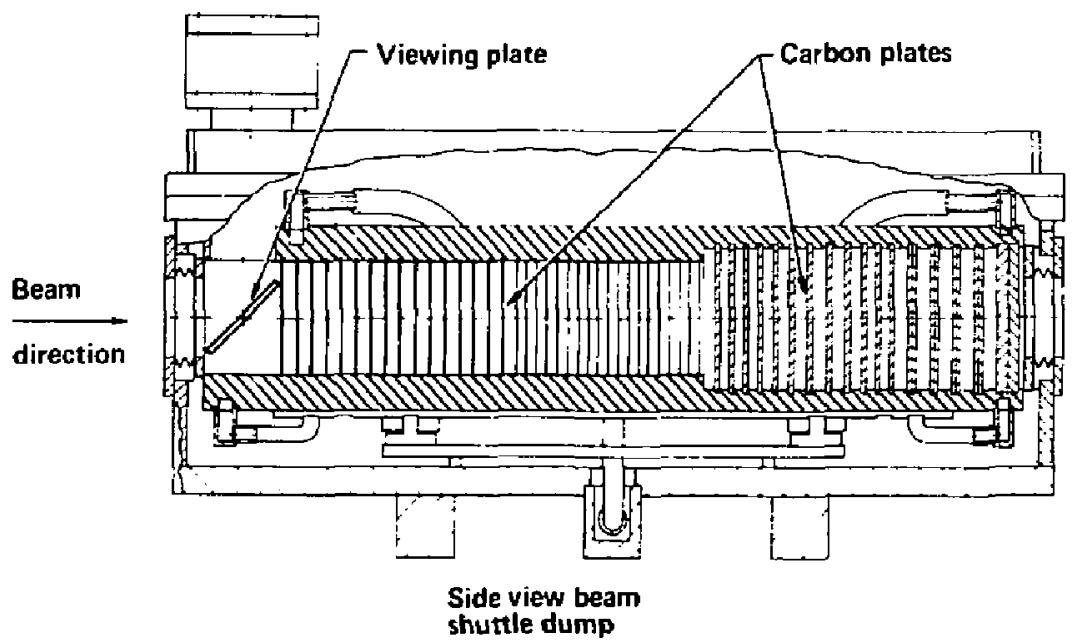

Figure 1. A schematic cross-sectional side view of the beam shuttle dump working upstream.

Electron-photon transport calculations have been made to determine the amount of energy deposited in these carbon plates inside the dump by the ATA electron beam. $^{3}$

The dostmetry measurements were performed outside the shuttle dump with the assistance of personnel from LLNL's Hazards Control Department who placed dosimeters $1 \mathrm{~m}$ apart along strings, which were attached at one end to the top of the center of the beam shuttle dump and at the other end to the tunnel wall. Seven strings were atcached between the dump and various locations along the wall defining angular positions of $24^{\circ}, 30^{\circ}, 45^{\circ}, 60^{\circ}, 90^{\circ}, 120^{\circ}$, $135^{\circ}, 150^{\circ}$, and $165^{\circ}$ as shown in Flgure 2. Small wax-paper envelopes were attached by safety clips to 30 known positions along the strings. Three Lif thermoluminescent chips ${ }^{4}$ sensitive to $x$-ray radiation were placed in each of the 30 envelopes, and three CR39 plastic wafers ${ }^{5}$ sensitive to fast neutrons were placed in envelopes at selected positions. One thermoluminescent chip and one CR39 plastic wafer, of the three exposed at each position, were used to set the reading process on the proper scale. Thus, two $x-$ ray and two neutron readings wer available for each measurement location. A photograph 


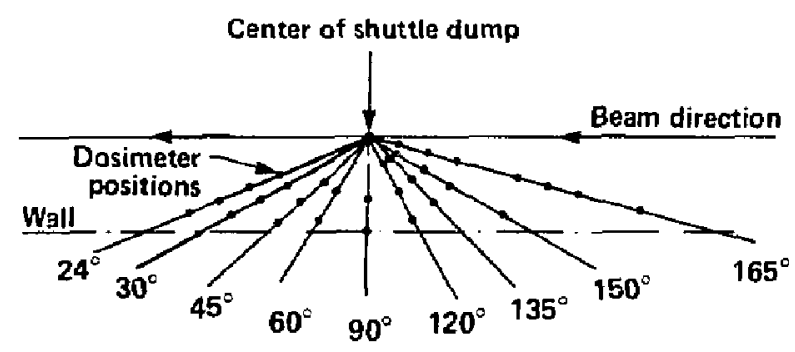

Figure 2. A schematic of the geometry of the surveyed dosimeter positions showing angles and distances relative to the center of the shuttle dump and electron beam direction.

of the matrix of dosimeters suspended from the strings around the shuttle dump is shown in Figure 3 .

The first set of measurements was taken on the beam shuttle dump January 9, i 385 . The accelerator operator delivered approximately $5 \mathrm{kA}$ of current at a beam energy of $37 \mathrm{MeV}$ into the shuttle dump. Approximately $0.037 \mathrm{kA}$ of current was transmitted through the shuttle and was eventually stopped in carbon in the beamline beyond the shuttle dump. After the accelerator was properiy tuned and stabilized, the pulsed power to the injector and accelerator was switched off. The experimenters then entered the target area and placed the dosimeters in the envelopes at the previously surveyed locations marked along the string. After returning to the control room, the pulsed power was switched on and a counter recorded the number of electron pulses. After approximately $11 \mathrm{~min}, 758$ pulses were recorded and the pulsed power was again switched off. The total charge deposited in the shuttle dump by the electrons was determined from $Q=758$ pulses $\times 50 \times 10^{-9}$ s/pulse $\times 5 \times 10^{3} \mathrm{C} / 5$ and is equal to $0.19 \mathrm{C}$. The experimenters, together with personnel from Hazards Control, entered the target area to retrieve the dosimeters, which were then stored for future readout. Similar exposure and recovery procedures were followed on April 12 and on December 23. 1985, except that the dosimeters were placed around the beam stop at the end of the propagation tank. Accumulated charge was more carefully determined by integrating the beam current monitor signal from the dump area and summing over all the shots. A schematic of the beam stop for the second set of measurements is shown in Figure 4 . 


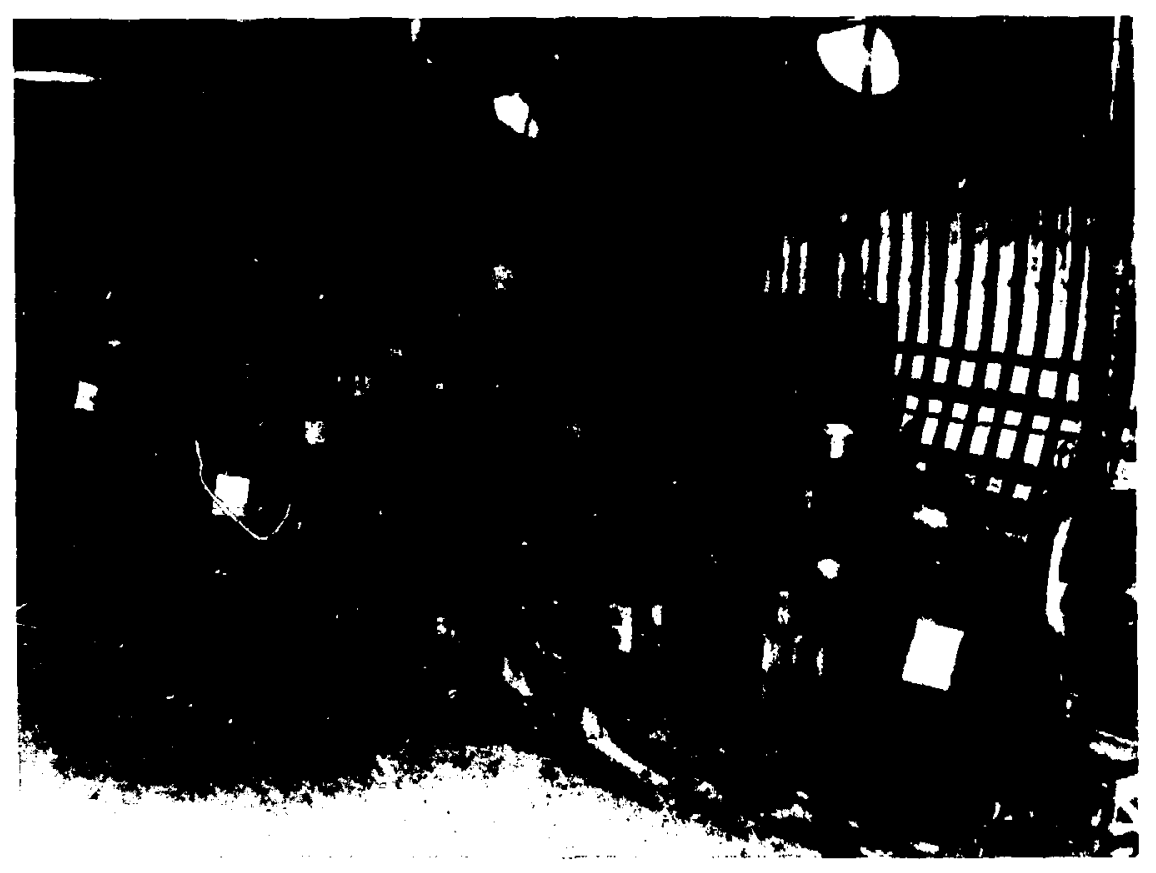

Figure 3. A photograph of the shuttle dump and dosimeters suspended in position. 


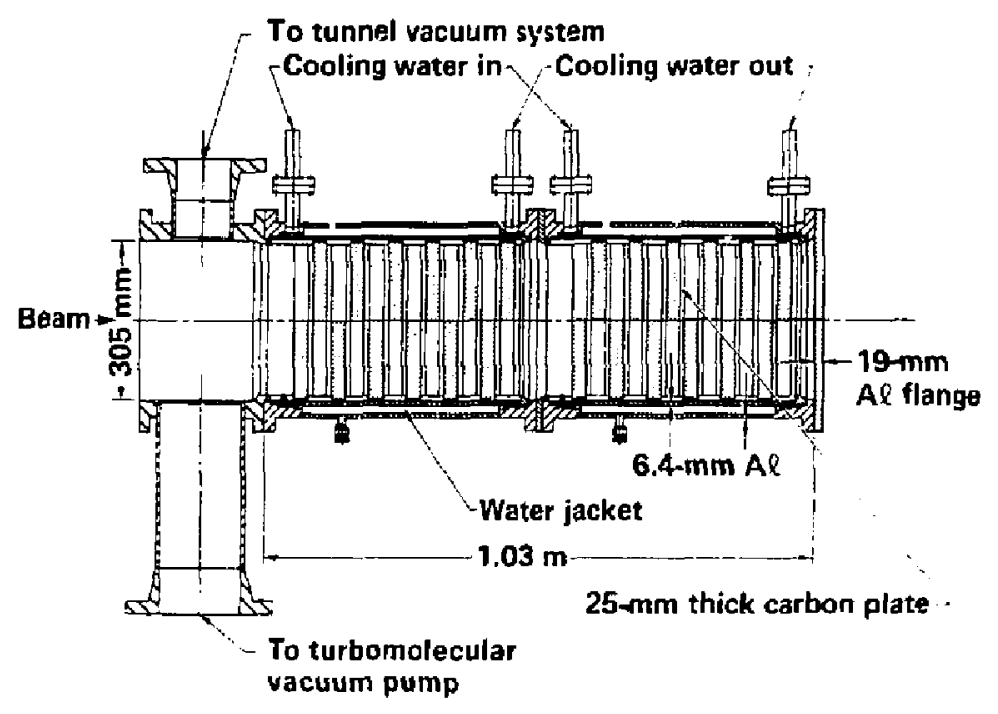

Figure 4. A schematic of the cross-sectional side view of the beam stop.

3. Calibration of the Dosimeters

The $x$-ray thermoluminescent dosimeters (TLD) were read out by LLNL's Hazards Control Department. The TLDs consist of three Lif crystals in a plastic holder about $4 \mathrm{~cm}$ in diameter. Radiation elevates the Lif crystal into trapped higher energy states. When heated by hot, dry nitrogen. the Lif crystals return to the ground state and emit visible light. Using a photo-electron multiplier tube and suitable electronics, the roentgen dose to the LIF crystal can be determined. The system is calibrated by exposing the dosimeters to radioactive sources ${ }^{60} \mathrm{Co}$ and ${ }^{137} \mathrm{Cs}$ of known intensity. Each position had two dosimeters; hence we record in Table 1 the average value in units of roentgens together with position number, angle, and distance, and the tabulated error is taken as the standard deviation of the mean value.

The neutron plastic wafers, which were supplied by Hazards Control, were calibrated using a ${ }^{252} \mathrm{Cf}$ spontaneous fission source. It was known that the 
Table 1. January 9, 1985, exposure $(Q=0.19 \mathrm{C})$.

\begin{tabular}{|c|c|c|c|c|}
\hline Position & $\begin{array}{l}\text { Angle } \\
\text { (deg) }\end{array}$ & $\begin{array}{l}\text { Distance } \\
\text { (meters) }\end{array}$ & $\begin{array}{c}\text { Dose } \\
\text { (roentgens) }\end{array}$ & $\begin{array}{l}\text { Neutron fluence } \\
\left(\mathrm{n} / \mathrm{cm}^{2}\right)\end{array}$ \\
\hline 1 & 24 & 3 & $1476 \pm 204$ & $3.1 \times 10^{8}=5 \%$ \\
\hline 2 & 24 & 5 & $469 \pm 28$ & 1.8 \\
\hline $3^{a, b}$ & 24 & 6 & $360 \pm 36$ & 1.6 \\
\hline $4^{a, b}$ & 30 & 3 & $16.7 \pm 10.3$ & 3.2 \\
\hline 5 & 30 & 4 & $867=i 32$ & 2.5 \\
\hline 6 & 30 & 5 & $495 \pm 18$ & 2.0 \\
\hline 7 & 45 & 3 & $1218 \geq 183$ & 3.5 \\
\hline 8 & 60 & 3 & $830=14$ & 3.9 \\
\hline 9 & 90 & 3 & $235=5$ & 3.4 \\
\hline 10 & 120 & 3 & $139 \pm 10$ & 2.0 \\
\hline 11 & 135 & 3 & $125=10$ & 1.7 \\
\hline 12 & 150 & 2 & $98 \pm 4$ & 1.8 \\
\hline 13 & 150 & 3 & $98 \pm 4$ & 1.8 \\
\hline 14 & 150 & 5 & $56 \pm 1$ & 1.3 \\
\hline 15 & 165 & 1 & $1294 \geq 225$ & 2.7 \\
\hline 16 & 165 & 3 & $126 \pm 7$ & 0.9 \\
\hline 17 & 165 & 5 & $39 \pm 4$ & 0.7 \\
\hline $18^{a}$ & 165 & 9 & $6.6 \pm 0.5$ & 0.4 \\
\hline 19 & 24 & 4 & $836 \pm 11$ & -- \\
\hline 20 & 45 & 2 & $3169=44$ & $\cdots$ \\
\hline 21 & 45 & 4 & $67\}=20$ & -- \\
\hline 22 & 60 & 2 & $1706 \leq 563$ & -- \\
\hline 23 & 90 & 2 & $426 \pm 9$ & -- \\
\hline 24 & 120 & 1 & $329=9$ & --- \\
\hline 25 & 120 & 2 & $239 \pm 13$ & --- \\
\hline 26 & 135 & 1 & $157 \pm 9$ & -- \\
\hline 27 & 135 & 2 & $211 \pm 21$ & --- \\
\hline 28 & 150 & 1 & $943 \pm 66$ & --- \\
\hline $29^{\mathrm{b}}$ & 165 & 2 & $69.7 \pm 48$ & --- \\
\hline $30^{a}$ & 165 & 7 & $9.3 \pm 0.05$ & --- \\
\hline
\end{tabular}


source produced $2.51 \times 10^{3} \mathrm{n} / \mathrm{s}$. Therefore, at $1 \mathrm{~m}$ from the source, the neutron fluence was $1.997 \times 10^{3} \mathrm{n} / \mathrm{s}-\mathrm{cm}^{2}$ assuming isotropy. The plastic wafers were exposed at 1 in for $2.68 \mathrm{~h}$, and $706 \mathrm{tracks} / \mathrm{cm}^{2}$ were recorded corresponding to a calibration factor of $1 \mathrm{n} / \mathrm{cm}^{2}=t r a c k s / \mathrm{cm}^{2} / 3.66 \times 10^{-5}$. The final neutron fluence results are tabulated in Table 1.

On Apri1 12 and December 23, 1985, a similar set of x-ray radiation and neutron dosimetry measurements were made in the diagnostics tunnel. In this case, the beam passed through the shuttle and stopped in the water-cooled carbon beam dump at the end of the beamline. Approximately $0.21 \mathrm{C}$ af electrons having an energy of $39=1 \mathrm{MeV}$ were delivered to the end beam dump. The results of the dosimetry measurements are tabulated in Table 2. Measurements taken on December 23 at $E_{0}=42 \pm 1$ MeV are shown in Table 3.

\section{Discussion of Results}

The shuttle dump is a complex oistributed source of radiaticn. It is a large rectangular aluminum box in which the electron beam loses energy by passing through a series of carbon plates over a distance of about $1 \mathrm{~m}$. The carbon is surrounded by water-cooled plates and other materials that present different shielding thicknesses to the radiation. In addition, dosimeters at $24^{\circ}$ and $165^{\circ}$ and perhaps at $30^{\circ}$ were partially obstructed by support materials surrounding quadrupole magnets. Since there is no simple geometrical symmetry in the shielding or radiation source, interpretation of the final dosimetry results by comparison with calculations is difficult.

Although the radiation source is not a simple point source, we have, for purposes of conveniently comparing the dose at different distances, normalized all doses to $1 m$ by assuning the dose decreases with distance as $r^{-2}$. Therefore, the $x$-ray dose tabulated in Table I is divided by the total charge $\left(Q=0.19 \mathrm{C}\right.$ ) and multiplied by $r^{2}$ and plotted in units of $R-m^{2} / C$ in figure 5 . Different symbols are usen to characterize the dose measured at various distances. Examination or the plot shows that for angles less than or equa! to $90^{\circ}$. the normalized doses at particular angles are consistent with each other, indicating that at forward angles the absorbed dose is decreasing as $r^{-2}$ over distances of at least 2 to $4 \pi$. Beyond $90^{\circ}$ there is greater scatter in the data, refiecting the fact that the point-source asproximation is simpiy invailo. To find a better fit to the radial dependence of the dose 
Table 2. April 12, 1985, exposure $\langle Q=0.21 \mathrm{C}\rangle$.

\begin{tabular}{|c|c|c|c|c|}
\hline TLD & $\begin{array}{l}\text { Angle } \\
\text { (deg) }\end{array}$ & $\begin{array}{c}\text { Distance } \\
\text { from center } \\
\text { (meters) }\end{array}$ & $\begin{array}{c}\text { Dose } \\
\text { (roentgens) }\end{array}$ & $\begin{array}{l}\text { Neutron fluence } \\
\left(\mathrm{n} / \mathrm{cm}^{2}\right)\end{array}$ \\
\hline 81569 & 0 & 3.0 & $2.03 \times 10^{4}$ & Saturated \\
\hline 63 & 0 & 18.0 & 3830 & $1.40 \times 10^{8}=5 \%$ \\
\hline 61 & 0 & 33.0 & 2660 & 0.70 \\
\hline 60 & 0 & 40.5 & 1030 & 0.39 \\
\hline 59 & 0 & 48.0 & 155 & 0.27 \\
\hline 58 & 0 & 55.5 & 121 & 0.24 \\
\hline 57 & 0 & 63.0 & 93 & 0.20 \\
\hline 56 & 0 & 70.5 & 68 & 0.17 \\
\hline 55 & 0 & 78.0 & 52 & 0.18 \\
\hline 65 & 30.0 & 33.0 & 63 & 8.93 \\
\hline 66 & 30.0 & 25.5 & $16 ?$ & 0.15 \\
\hline 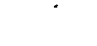 & 30.0 & 18.0 & 390 & 0.35 \\
\hline 68 & 30.0 & 10.5 & 353 & 1.04 \\
\hline 70 & 18.3 & 3.0 & 524 & 1.60 \\
\hline 71 & 44.7 & 3.0 & 882 & 1.44 \\
\hline 72 & 71.7 & 3.0 & 2109 & 1.67 \\
\hline 73 & 75.0 & 3.0 & 1280 & 1.46 \\
\hline 74 & 90.0 & 3.0 & 4708 & 1.67 \\
\hline 75 & 102.9 & 3.0 & 2740 & 1.57 \\
\hline 76 & 124.7 & 3.0 & 2319 & 1.47 \\
\hline 37 & 132.5 & 3.0 & 1793 & 1.46 \\
\hline 78 & 143.6 & 3.0 & 1720 & 1.37 \\
\hline 79 & 168.3 & 3.0 & 2319 & 1.38 \\
\hline
\end{tabular}


Table 3. Dacember 23, 1985, exposure $(Q=0.0028 \mathrm{C})$.

\begin{tabular}{rccc}
\hline TLO & $\begin{array}{c}\text { Angla } \\
(\text { deg) }\end{array}$ & $\begin{array}{c}\text { Distance } \\
\text { from center } \\
\text { (meters) }\end{array}$ & $\begin{array}{c}\text { Dose } \\
\text { (roentgens) }\end{array}$ \\
\hline 850240 & 0 & 5 & $172.3 \pm 7.2$ \\
41 & 0 & 8 & $83.9 \pm 2.7$ \\
42 & 0 & $1 ! .1$ & $46.1 \pm 1.0$ \\
43 & 0 & 14.1 & $40.8 \pm 2.4$ \\
44 & 0 & 17.2 & $30.9 \pm 1.2$ \\
45 & 0 & 20.2 & $34.8 \pm 17$ \\
\hline
\end{tabular}

ac back angles and reduce this scatter, the dose $i r i C$ is plotted versus the $\log$ of the distance and compared to assumed $r^{-1}, r^{-2}$, and $r^{-3}$ radial dependence. as shown in Figure 6. It appears that $r^{-2}$ fits better at smaller distances and $r^{-3}$ at greater distances. One would not expect this. since the shuttle represents a radiation source somewhere between a point source and a line source. Thus, some combination of $r^{-1}$ and $r^{-2}$ should fit the data. It is possible that the dosimeters farthest froin the source at $165^{\circ}$ may be partially shielded from the primary radiation source by the support structure of the entrance quadrupole, resulting in lower readings.

Results from a Monte Carlo electron-photon shower calculation using the computer code SANuiti 7 is given by the solid line in Figure $\ddot{j}$. The calculation was performed in three-dimensional geometr. , anj the important components of the shuttle dump were modeled using combinational geometry. The energy deposited in Lif dosimeters at a fixed Jistance of $1 \mathrm{~m}$ from the cencer of the shuttle dump between $0^{\circ}$ and $90^{\circ}$ was calculated by following 10,000 electrons down to a cutoff energy of $10 \mathrm{keV}$. The agreement between the calculation and data at $30^{\circ}$ is provably fortuitous: components of the support structure of the beamline obscure the direit line-of-sight between the center of the shuttle and the dosimeters at $24^{\circ}$ and $30^{\circ}$, and this factor was not included in the calculation. One possible explanation of why the calculation undershoots the data at $45^{\circ}$ and $60^{\circ}$ is that we are incorrectly normalizing the data to 1 in by multiplying by $r^{2}$. Another possibility is that there is an 


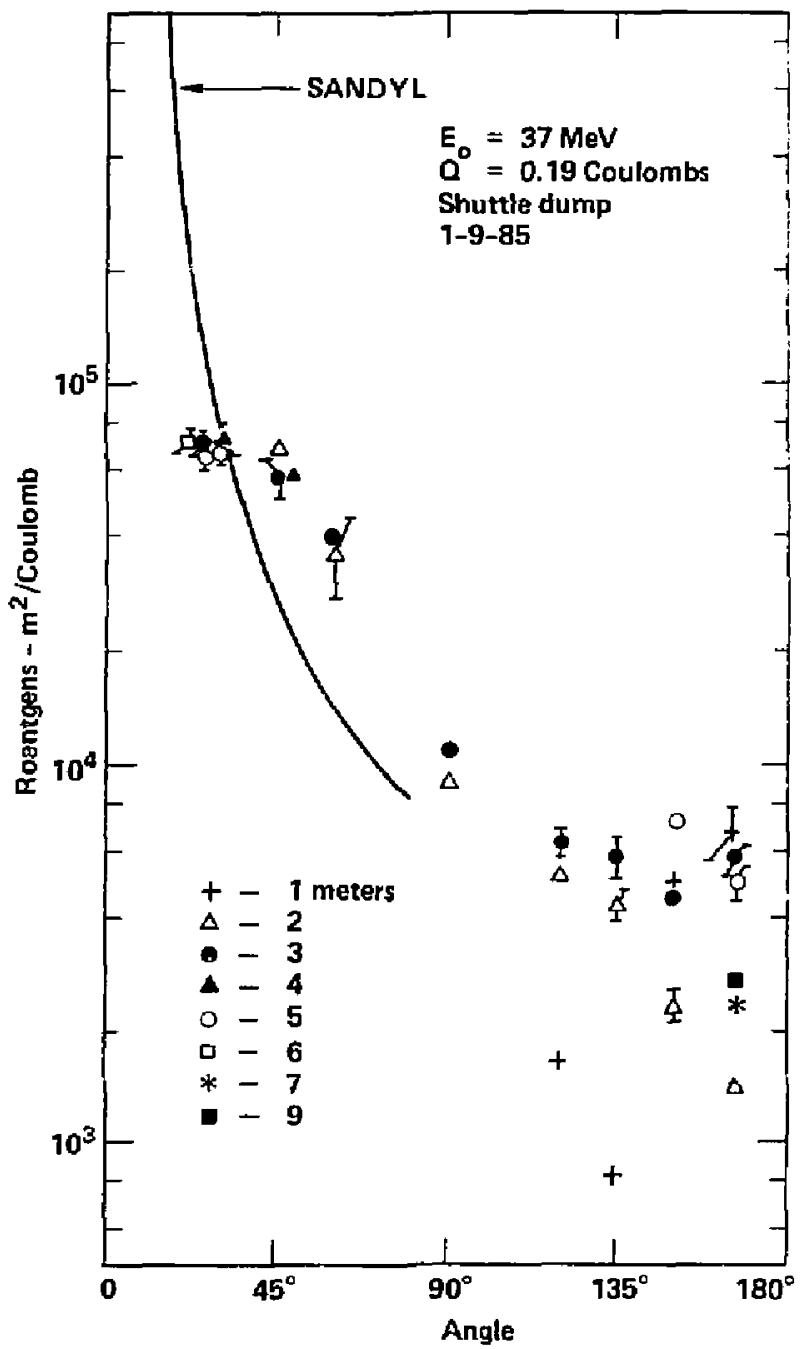

Figure 5. Angular distribution of the x-ray radiation dose multiplied by the square of the distance compared to the calculated dose 1 m from the center of the shuttle dump. 


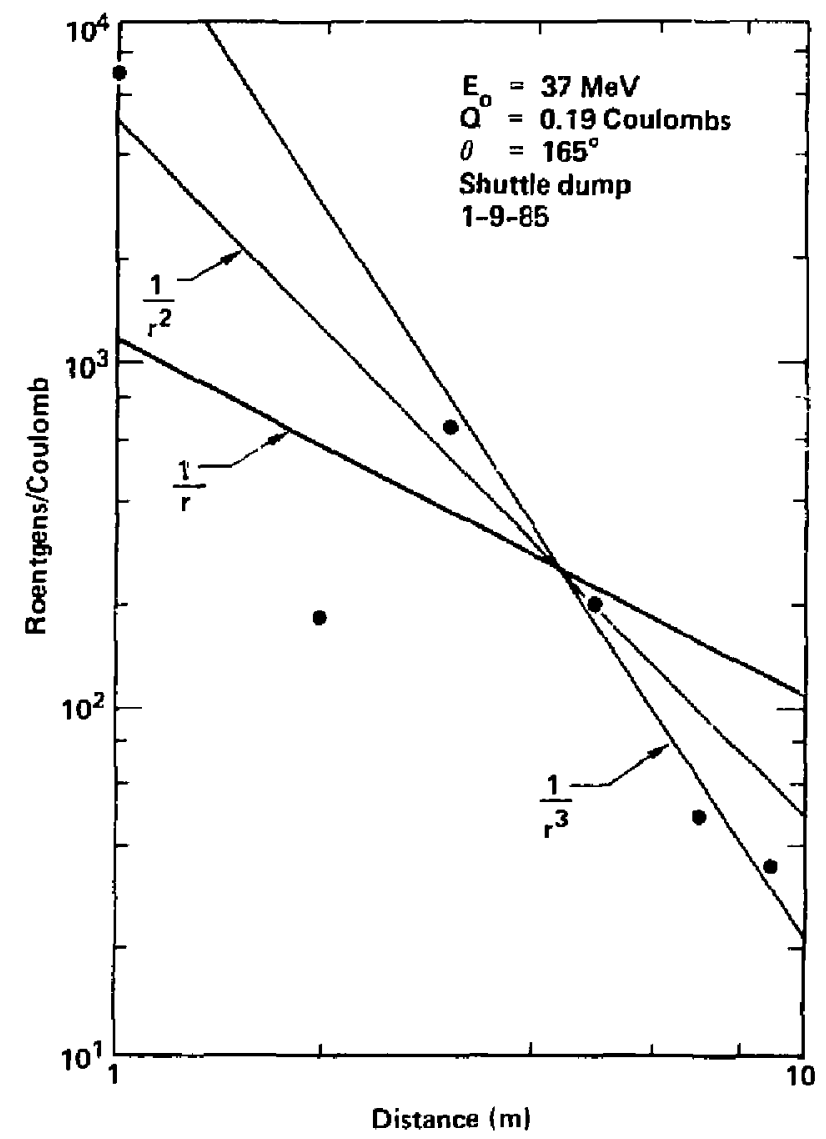

Figure 6. A plot of the measured $x$-ray radiation dose at $\theta=165^{\circ}$ versus the distance between the center of the shuttle dump and dosimeter. 
additional source of radlation originating upstream caused by the beam halo or by a mis-steered beam striking the sides of collimators as it passes through them. The dosimeters in the forward direction and closest to the beam tube would intercept more of the forward-scattered radiation caused by the beam spiil. More detalled plots iliustrating the angular distributions of the $x$-ray radiation dose for measurements at fixed distances at 2,3 , and 5 m are shown in Figures 7,8 , and 9 .

The neutron radiation fluence per coulomb is plotted versus the log of the distance between the dosimeter and the center of the shuttle for fixed angles of $24^{\circ}, 30^{\circ}, 150^{\circ}$, and $165^{\circ}$ in Figure 10 . The smooth i ine through the data is an eyeball fit assuming the radiacion decreases with distance as $r^{-1}$. This is consistent with an assumed line source of neutrons and inconsistent with a $r^{-2}$ decrease, which best descrtbed the $x$-ray radiation at forward angles.

The neutron fluence plotted in Figure in is multiplied by the distance in $m$ to account for the $r^{-1}$ dependence, and all the data is plotfed versus angle in Figure 11 . The peak neutron yield is about $6 \times 10^{9} \mathrm{n}-\mathrm{m} / \mathrm{m}^{2}-\mathrm{C}$ at $\theta=60^{\circ}$. Using the published neutron yield ${ }^{2}$ for $34-\mathrm{MeV}$ electrons on carbon and assuming isotropy, the deduced yield to be compared with the data in Figure 11 is $1.3 \times 1 \mathrm{c}^{10} \mathrm{n}-\mathrm{m} / \mathrm{cm}^{2}-\mathrm{C}$, which is about twice as high. Absorption of neutrons by the carbon and shuttle dump walls has not been included in this estimate.

In Figures 12, 13, and 14, the $x-r a y$ and neutron dose measurements made on April 12, 1985, are plotted. Additional measurements made on December 23. 1985, are plotted as triangles in Figure 12 . Between 50 and $90 \mathrm{~m}$, the $x-r a y$ dose decreases with distance as $r^{-2}$, as might be expected far from the source of the radiation. Again using Ref. 1, the $x$-ray dose at $0^{\circ}$ from a $39-$ to $42-\mathrm{MeV}$ electron beam incident on a high-z target optimized for emission rate is $9 \times 10^{5} \mathrm{rads}-\mathrm{m}^{2}(\mathrm{~mA})^{-1} \mathrm{~min}^{-1}$ or $1.51 \times 10^{7} \mathrm{R}-\mathrm{m}^{2} / \mathrm{C}$. For low-2 material $(Z=6)$ assuming a $Z^{1 / 2}$ dependence, ${ }^{6}$ the yield is reduced by a factor of 0.34 . Since the carbon bean stop is about $30 \mathrm{~cm}$ long and the electron range is about $11 \mathrm{~cm}$, the emitted $x$-ray yield will be attenuated at least by the remaining $19 \mathrm{~cm}$ at $0^{\circ}$. Assuming exponential attenuation with $\mu=0.05 \mathrm{~cm}^{2} / \mathrm{gn}$ for a $1-\mathrm{MeV}$ photon, we get a reduction factor of 0.10 .

The expected dose $1 \mathrm{~m}$ from the carbon beam stop at $0^{\circ}$ becomes $5.2 \times 10^{5}$ 


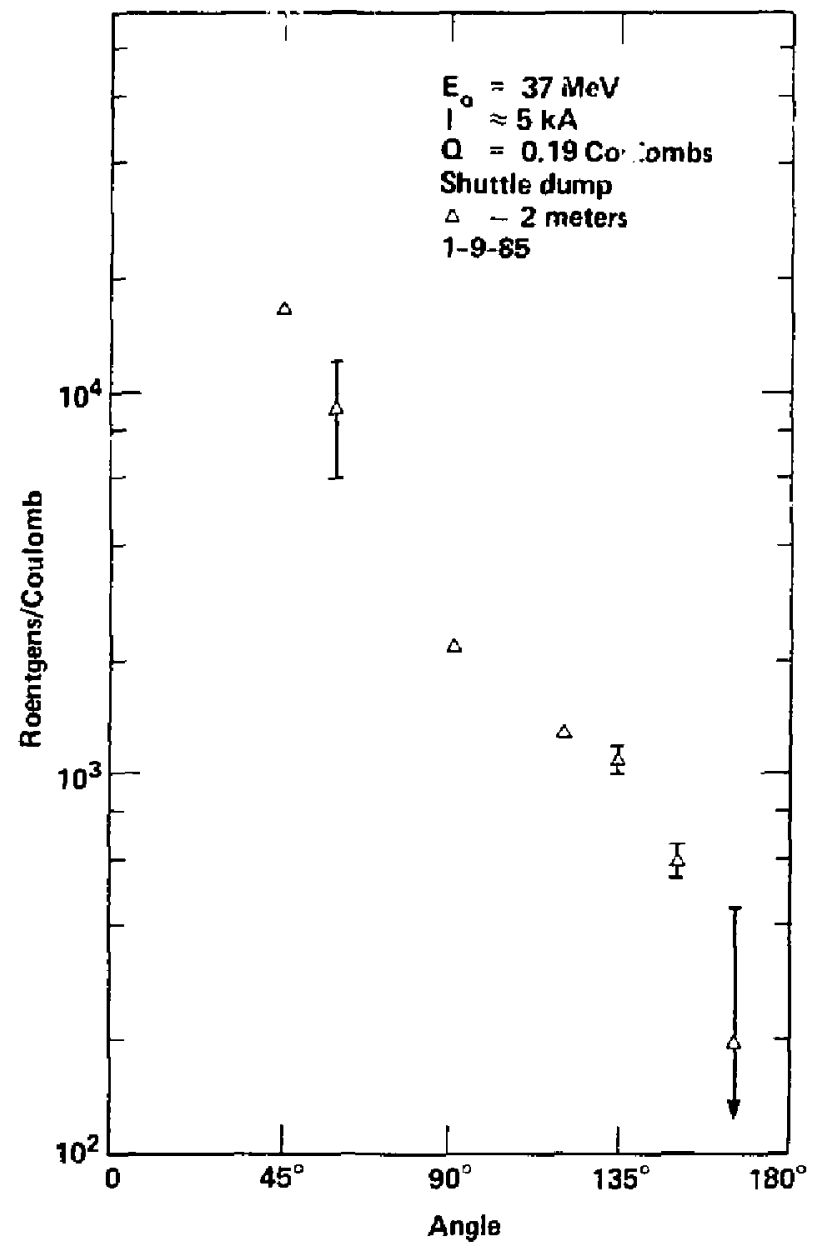

Figure 7. Angular distribution of the $x$-ray radiation dose measured $2 m$ from the center of the shuttle dump. 


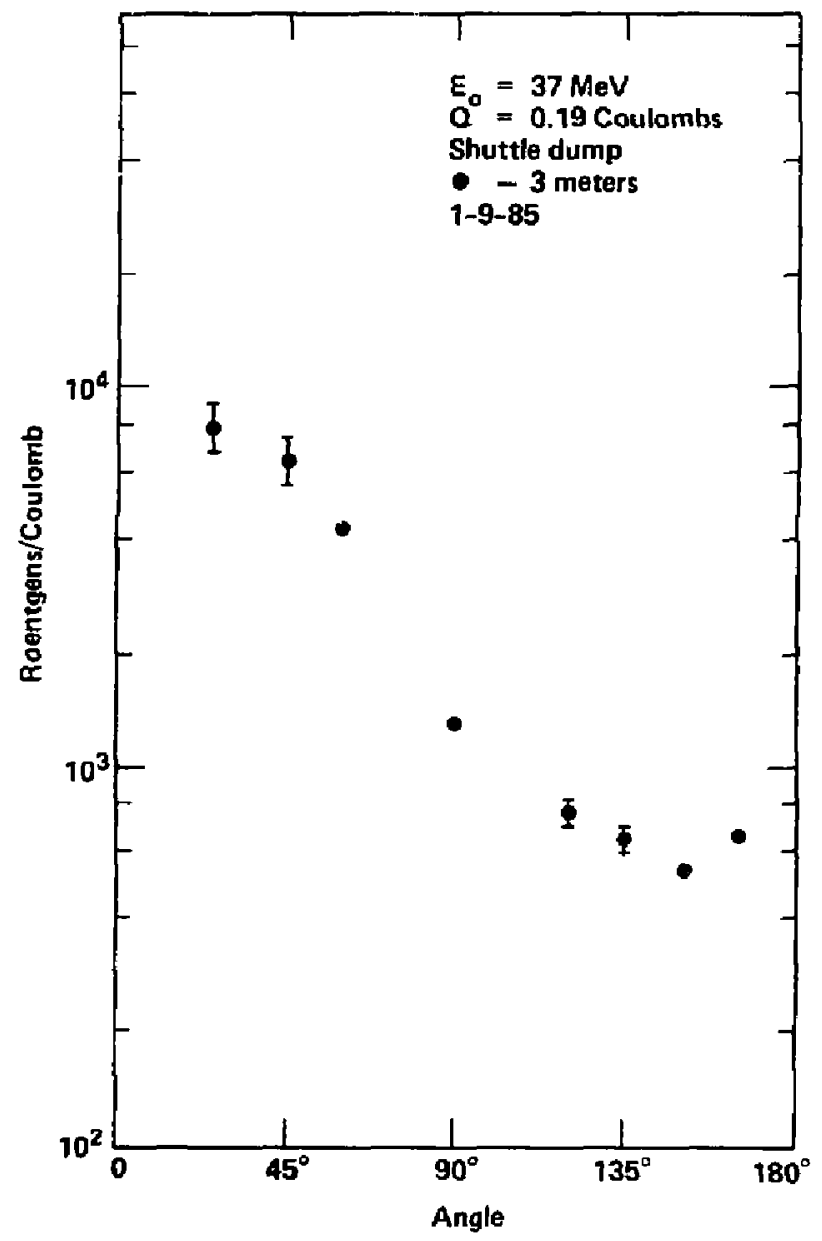

Figure 8 . Angular distribution of the $x$-ray radiation dose measured $3 m$ from the center of the shuttle dump. 


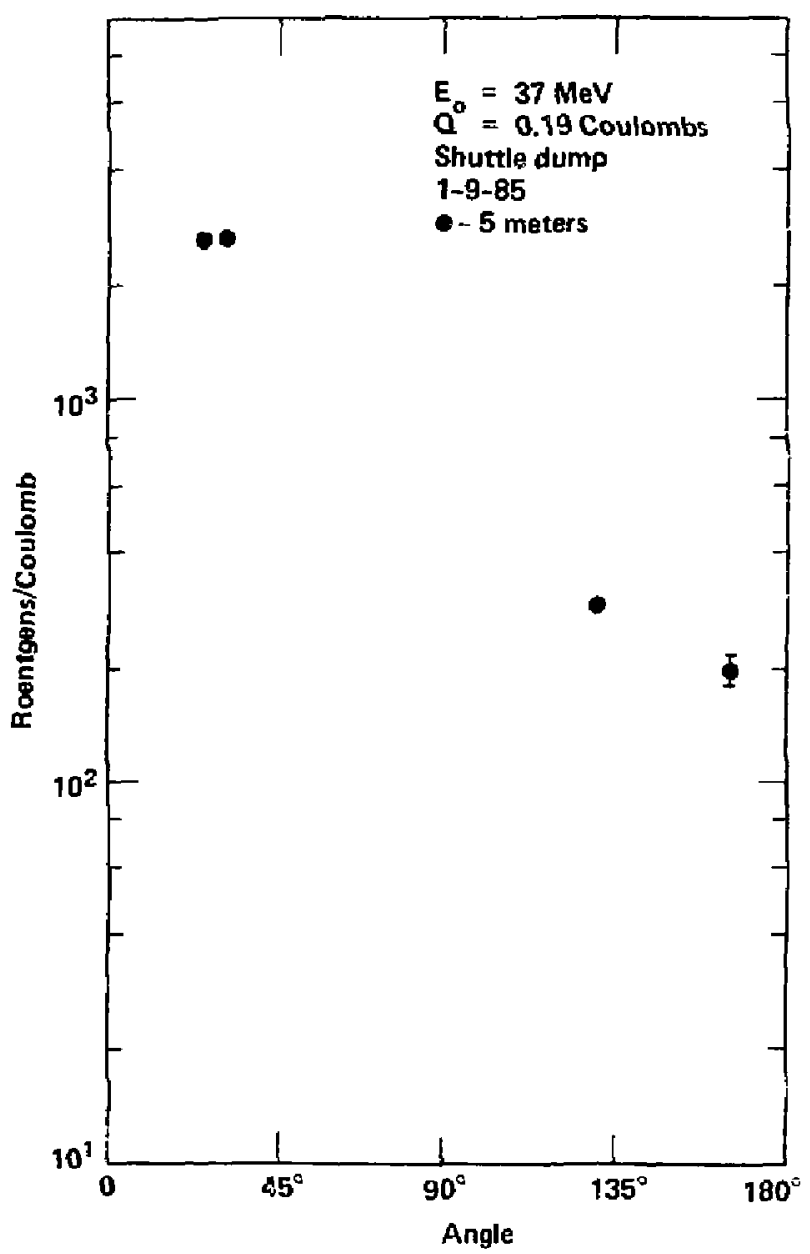

Figure 9. Angular distribution of the $x$-ray radiation dose measured $5 \mathrm{~m}$ from the center of the snuttle dump. 


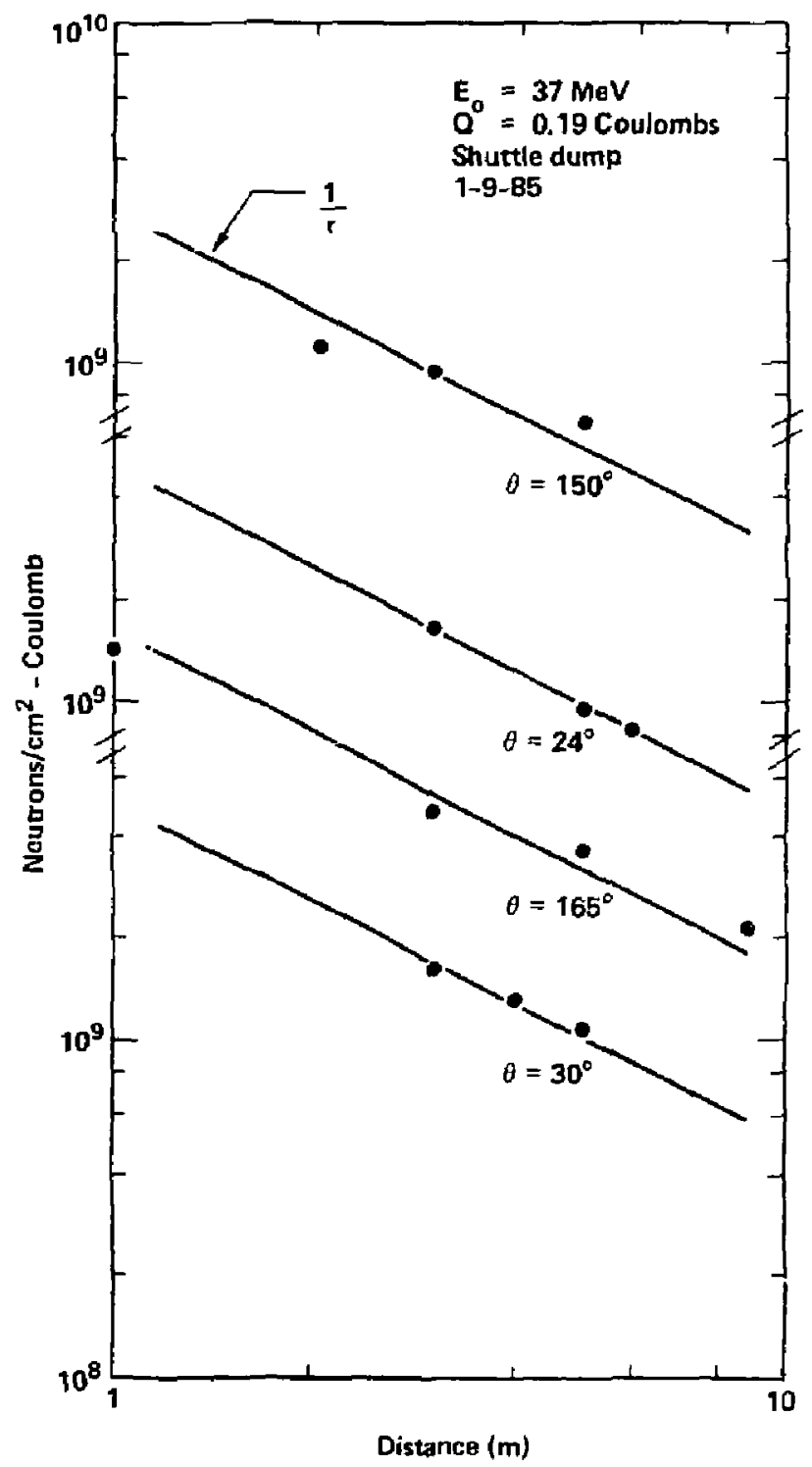

Figure 10. A plot of the neutron fluence versus distance for selected angles. 


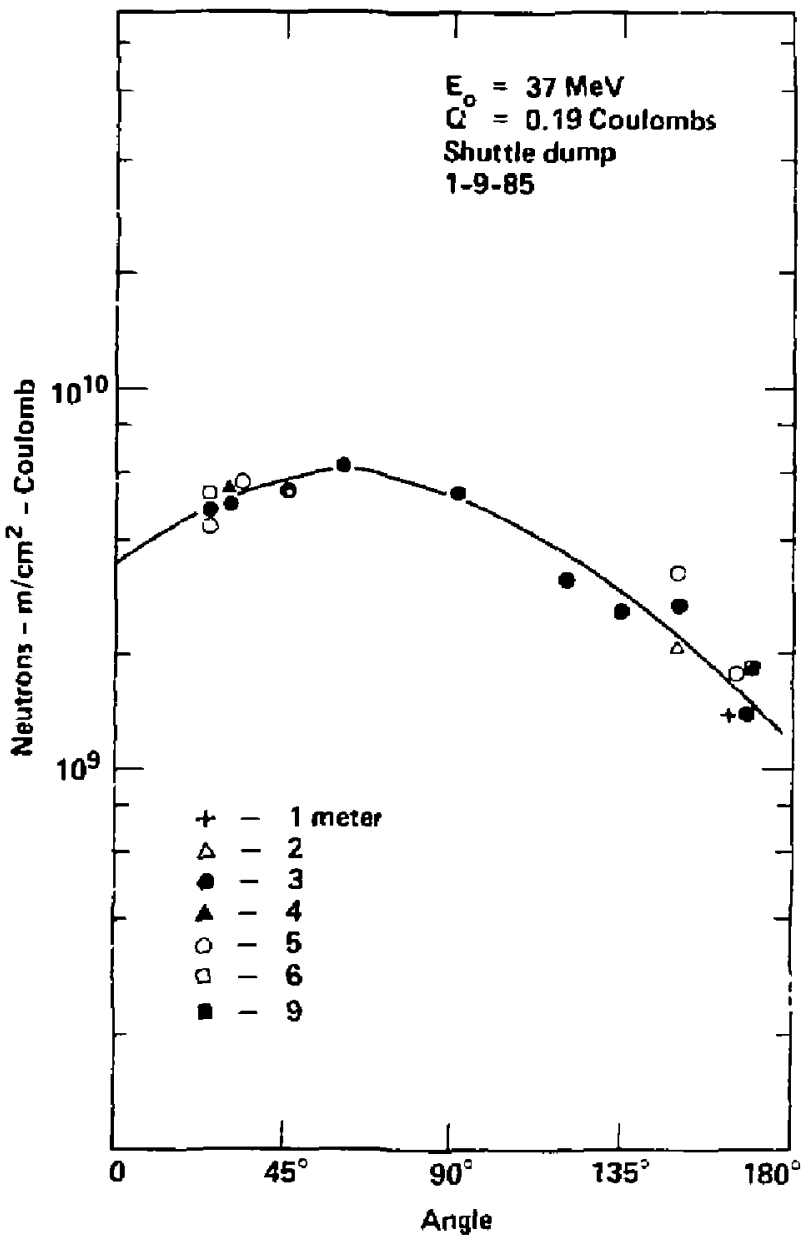

Flgure 11. Angular distributions of the nevirion fluence rautiolied by the distance from the center of the shuttle dump. (The curve through the data is to guida the eye.) 


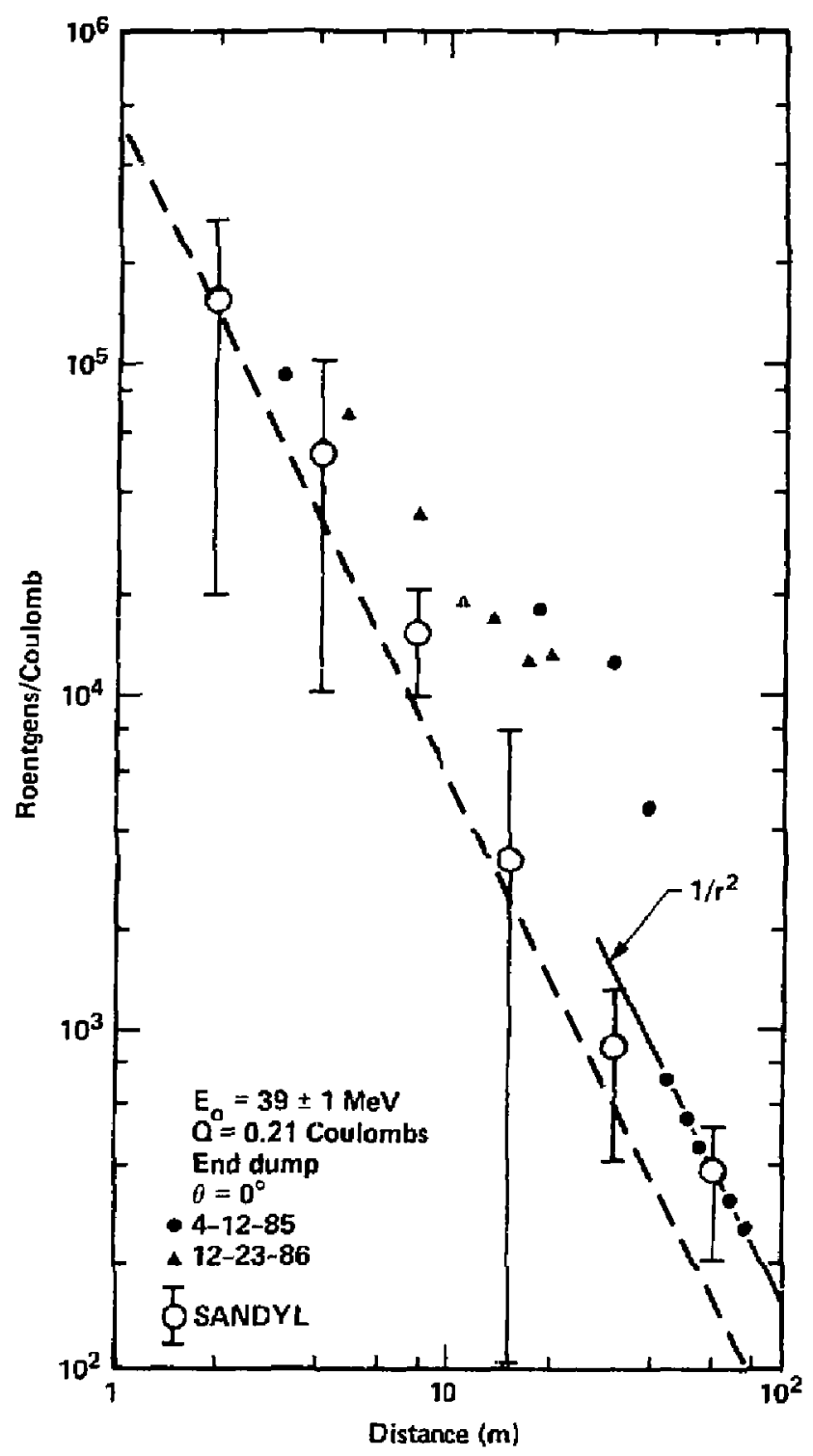

Figure 12. A plot of the $x$-ray radiation dose at $\theta=0^{\circ}$ versus distance measured from the center of the end beam dump. 


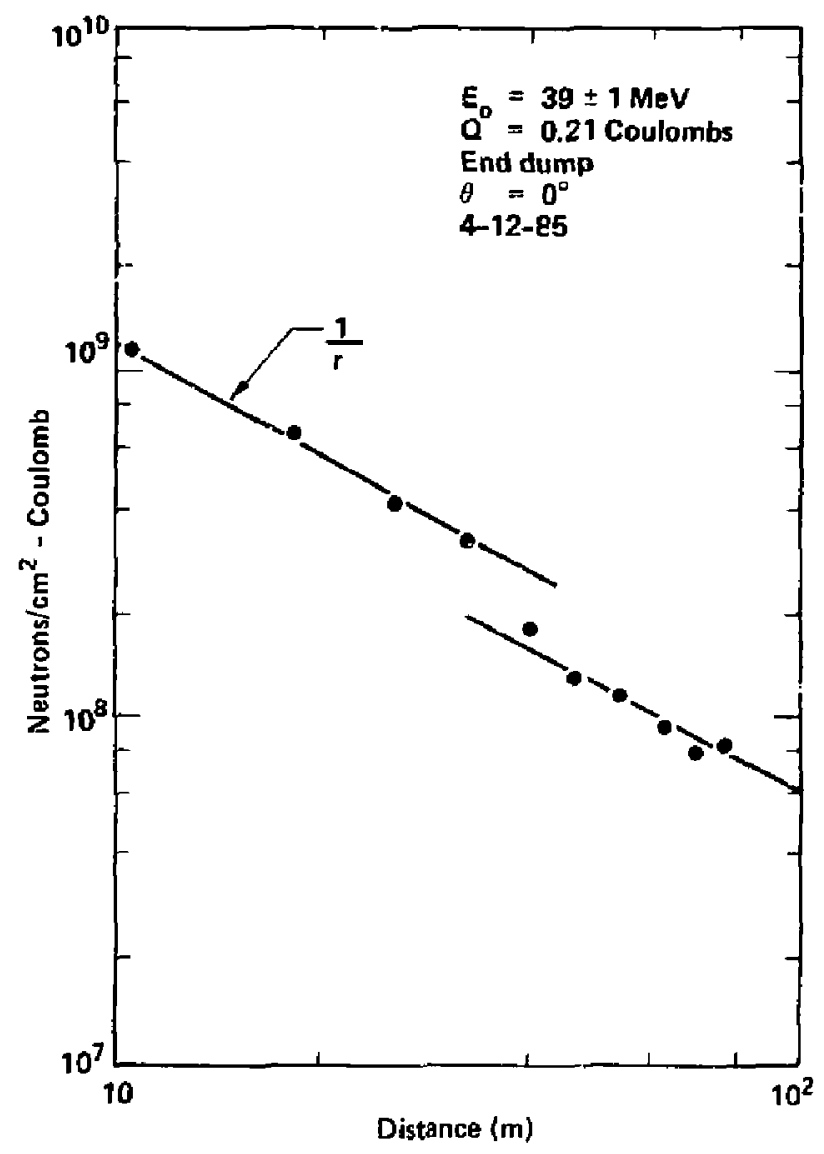

Figure 13. A plot of the neutron fluence at $\theta=0^{\circ}$ versus distance measured from the center of the end beam dump. 


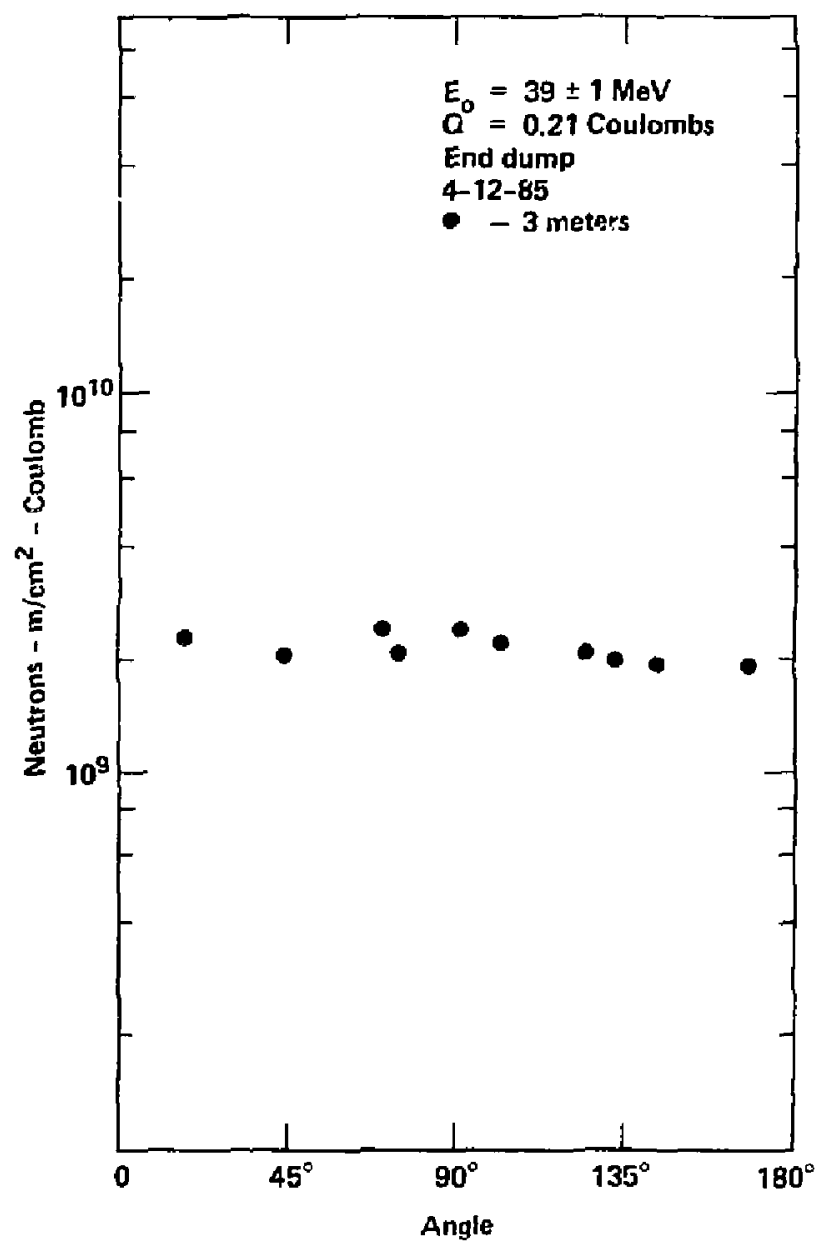

Figure 14. Anguiar distribution of the neutro? fluence multiplied by the distance from end beam dump $(3 \mathrm{~m})$. 
$R-m^{2} / C$. Assuming a point source and, thetefore, a $r^{-2}$ decrease in dose with distance, the dose is calculated and the result is plotted as a dashed stralght line in Figure 12 . The measured dose is about 2 to 5 times larger than this crude estimate. Results from a Monte Carlo electron-photon shower calculation using the computer code SANDYL, as described earlier, 7 are plotted as open circles together with statistical errors in Figure 12. This comparison shows that the calculation and the data are in agreement for distances less than $5 \mathrm{n}$ and greater than $50 \mathrm{~m}$ from the center of the carbon beam stop. In between, the measured dose is oefinitely higher than predicted, and a pronounced bump occurs in the data in the 20 - to $40-m$ range. The dose measurements were made on two occasions and are roughly consistent. The origin of this radiation enhancement is not known. One interesting possibility is that photon radiation reflected from the walls of the diagnostic tunnel could produce this effect.

It is also interesting to note that the neutron dose at $0^{\circ}$ decreases with distance as $r^{-1}$ to a distance of about $30 \mathrm{~m}$ and not as $r^{-2}$ as shown in Figure 13. Near $40 \mathrm{~m}$ an abrupt decrease in dose takes place, and then beyond $50 \mathrm{~m}$ the dose again decreases as $\mathrm{r}^{-1}$. The angular distribution of neutron dose at $3 \mathrm{~m}$ is isotropic as expected and is shown in Flgure 14. Realistic neutron calculations were not performed.

\section{Radiation Damage}

Threshold levels for damage to electronic components such as transistors and resistors resulting from $x$-ray radiation is typically $10^{3}$ rads. 8 Inspection of Figure 5 shows that at $1 \mathrm{~m}$ from the shuttle dump the radiation dose is about $10^{4} \mathrm{R} / \mathrm{C}$ or $1.9 \times 10^{3} \mathrm{R}$ or $1.7 \times 10^{3} \mathrm{rads}$ for $Q=0.19 \mathrm{C}$, which corresponds to an exposure of $11 \mathrm{~min}$ for a 5-kA pulsed beam whose full width at half maximum is $50 \mathrm{~ns}$. At forward angles, the dose levels are an order of magnitude larger. It is clear, therefore, that $x$-ray radiation levels are sufficient to cause damage to unshielded instrumentation near the beam dum in a relatively short time. Damage in this case can be considered to have occurred when, for example, the current gain of the transistor begins to change as a resuit of exposure to radiation. (For more details see Ref. 8.)

Threshold levels for damage to electronics by neutrons are typicaliy $10^{12} \mathrm{n} / \mathrm{cm}^{2}$. From Flgure 10 , the peak neutron fluence levels at $1 \mathrm{~m}$ at 
an angle of $60^{\circ}$ are $6 \times 10^{9} \mathrm{n} / \mathrm{cm}^{2} / \mathrm{C}$. For our exposure of $11 \mathrm{~min}$, this corresponds to $1.1 \times 10^{9} \mathrm{a} / \mathrm{Cal}^{2}$. Since this level is $10^{3}$ lower than the threshold value, neutrons are not expected to be a source of radiation damage over short times. Such effects, however, will be cumulative.

\section{Conclusions and Future Studies}

The $x$-ray dosimetry measurements near the shuttle dump yield dose levels about a factor of 2 higher than that predicted by Monte Carlo calculations in the angular range $45^{\circ}$ to $90^{\circ}$. The disagreement between the data and the Monte Carlo calculation probably arises because the calculations were performed to yield the dose at $1 \mathrm{~m}$, and the data taken at 2 to 4 m were incorrectly normalized to $1 \mathrm{~m}$ assuming $r^{-2}$ fall-off. Estimates from published neutron fluence data are too high by a factor of 2 . Neutron Monte Carlo calculations were not performed. Further discrepancies between experiment and predictions have also been found for the $0^{\circ} x$-ray data taken at tha beam $s$ top (end dump) farther downstroam. Dose levels were found to be iarger by factors of 2 to 5 at distances of 5 to 40 m into the diagnostic tunnel. The effects of the walls of the tunnel were not included in the calculations and should be investigated further.

We emphasize that the comparison of the data with electron-photon-shower Monte Carlo calculations is not intended to be a "benchmark" test of the shower code. In fact, because the shuttle dump and beam stop have complex geometries and are in complex enviroments that are ery difficult to model in a transport code, we performed the measurements to gut a more raliable determination of the $x$-ray and neutron radiation yields than we would expect from calculation:.

On the other hand, there have been benchmark experiments to test Monte Carlo caiculations in simple slabs of solid materials ${ }^{9}$ ( $E_{0}=500 \mathrm{MeV}$ ) and liquids ${ }^{10}\left(E_{0}=100 \mathrm{MeV}\right)$. Generally, good agreement ( $\left.\leq 10 \%\right)$ is found between the forward angle off-axis dose measurements and the transport calculations.

For experiments now in the planning stage at the ATA that requtre the beam in open air, good predictions of the radiation levels are essential because it is not possible to shield against all radiatiori emanating from tine entire length of a diffused beam as it loses energy in the open air. 
Calculations of the spatial energy deposition in air by electron beams of energy $0.05,0.5,1.0$, and $10.0 \mathrm{GeV}$ have been performed by several authors. $11-13$ None of these calculations has heen checked against experiment. In open air it will be particularly important to estimate the leval of backscattered radiation or what is commonly known as "sky shine." Results from electron-photon shower codes such as SANDYL are not expected to be too reliable in the backward direction and have not beer tested against experimert in these geometries. At back angles, nucluar reactions such $(Y, 11)$ and inelastic nuclear electron scattering become increasingiy important because the coulomb cross reactions become successively weaker with increasing angle. Neutron production, electron induced fission, etc and subsequent gamina radiation are not included in the state-of-the-art electron-photon shower codes.

To study further and to provide a rigorous test of transpo:t caiculations including backward scattering geometries, new benchmark experiments have been proposed and are underway at various facilities. 14-17 


\section{REFERENCES}

1. National Council on Radiation Protection and Measurements, Radiation Protection Design Guidelines for 0.1-100 MeV Particle Accelerator Facilities, NCRP Report No. 51, NCRP, Washington, D.C., 1977 (p. 95).

2. International Atomic Agency, Radiological Safety Aspects of the Operation of Electron Linear Accelerators, Technical Reports Series No. 188, IAEA, Vienna, 1979, p. 87 .

3. Dennis Slaughter. Particle and Power Profile Calculations for the ATA Beam-Dump and Emittance Box, Lawrence Livermore National Laboratory. Livermore, CA, UCID-19561.

4. H. Cember, Introduction to Heaith Physics, (Permagon Press Inc. New York, 1969), p 251.

5. K. F. Petrock, A System for Reading Thermol uminescent Radiation Dosimeters Using a Heated Inert Gas, Hazards Control Progress Report No. 28, UCRL-50007-67-2, (1967), p 1. Also see K. F. Petrock and G. E. Shapiro, Extending the Low-Dose Capability of the LLL Hot Nitrogen TLD Reader, Mazards Control Progress Report No. 42, UCRL-50007-72-1, (1972). p 2.

6. See Ref. $1, p 98$.

7. H. M. Colbert, SANDYL: A Computer Program for Calculating Combined Photon-Electron Transport in Complex Systems, Sandia Laboratories, Livermore, CA, SLL-74-0012 (1974).

8. Components Response Information Center, Radiation Effects on Semiconductor Devices, Report NO. HDL-OS-77-1, CRIC, Harry Diamond Laboratories, Adelphi, MD (1977). 
9. E. Farley, K. Crase, and D. Selway, 500 MeV Electron Beam Benchmark Experiments and Calculations. Lawrence Livermore National Laboratory. Livermore, CA, UCRL-52871 (1979).

10. Patrick Frank Cromar, Comparison of Calcallations and Measurements of the Off-Axis Radiation Dose (Si) in Liquid Nitroger as a Functton of Radiation Length, Master's Thesis, (Naval Postgraduate School, Monterey, December 1984). Also see X. X. Maruyama, J. R. Nelghbours, and R. Fitzpatrick, Study of Off-Axis Radiation Exposure from Relativistic Electrons Traversing Through Matter, Naval Postgraduate School, Monterey, CA 93943.

11. R. A. Lindgren, Calculated Photon Spectra and Radiation Dose from $50 \mathrm{MeV}$ Electrons Stopping in Air, Naval Research Laboratory Memorandum Report 3335 (1976).

12. D. R. Slaughter. Calculated Photon Spectra at Several Angles for 5 and $50 \mathrm{MeV}$ Electron Bearn Striking Solid and Gas Targets. Lawrence Livermore National Laboratory,Livernore, CA, UCID-19741 \{1983\}.

13. S. Geer and A. Gsponer, "Radlation Dose Distributions Close to the Shower Axis Calculated for High Energy Electron Initiated Electromagnetic Showers in Air," Atomkernenerg Kerntech. (Germany) 43, 42 (1983).

14. S. H. Stern, R. A. Lindgren, M. H. Cha, O. F. Gottepe, and M. Hafter, A Benchmark Experiment to Test Monte Carlo Electron-Photon Shower Simulation Codes, Bates Linear Accelerator Center, Middleton, MA, Proposal 85-15 (1985). Also see M. H. Cha, "Electron-Photon Showers: Experiments and Calculation," Bull. Am. Phys. Soc. 31, 765 (1986).

15. J. A. Becker, R. W. Bauer, and W. E. Farley, Measurements of Return Radtation Produced by Energetic Electron Bombardment (document in progress), Lawrence Livermore National Laboratory, Livermore, CA (1987). 
16. R. W. Baver. J. A. Becker, and W. E. Farley, Measurements of Return Radiation Produced by ENergetic Electron Bombardment, II, Lawrence Livermore National Laboratory, Livermore, CA, UCIO-21119 (1987).

17. W. E. Farley, R. A. Lindgren, J. A. Becker, C. R. Wuest, S. Murty, and J. Behrens. A Benchmark Experiment to Test Monte Carlo Electron-Photon Shower Predictions of Observed Photon Fiux and Spectra from Thick Targets Eombarded with $850 \mathrm{MeV}$ Electrons, Bates Linear Accelerator Center. Middieton, MA, Proposal 87-01 (1987). 